\title{
Changes in physical activity and screen time related to psychological well-being in early adolescence: findings from longitudinal study ELANA
}

\author{
Viviane S. Straatmann ${ }^{1 *}$, Aldair J. Oliveira ${ }^{2}$, Mikael Rostila ${ }^{3}$ and Claudia S. Lopes ${ }^{1}$
}

\begin{abstract}
Background: Psychological well-being influences health behaviours differently in adolescent boys and girls. We evaluated the role of psychological well-being in early adolescence in the onset and persistence of insufficient physical activity and exceeding recommended screen time, depending on gender.

Methods: This work derives from a cohort study called Longitudinal Study of Adolescent Nutritional Assessment conducted among elementary school students from two public and four private schools in Rio de Janeiro, Brazil from 2010-2013. We analysed data from 2010 and 2012 from 526 adolescents. Physical activity was evaluated using the International Physical Activity Questionnaire. Those who performed less than 60 min per day of moderate to vigorous physical activity (MVPA) were classified as insufficiently active. Screen time was evaluated based on daily time spent in front of television, video games, and computers. Those who had $4 \mathrm{~h}$ or more screen time per day were classified as exceeding the recommended time. Psychological well-being was assessed using the psychological domain of the KIDSCREEN 27 questionnaire. Linear regression was used to estimate coefficient $(\beta)$ and $r^{2}$ values for continuous variables. Relative risks (RR) and confidence intervals ( $95 \%$ Cl) for onset and persistence of insufficient activity and exceeding recommended screen time were estimated with Poisson regression models.
\end{abstract}

Results: Among girls, linear regression analyses showed a significant inverse association between psychological wellbeing and screen minutes per day at T2 $\left(r^{2}=0.049 / \beta=-3.81(95 \% \mathrm{Cl}-7.0,-0.9)\right)$, as well as an association between poor psychological well-being and onset of exceeding recommended screen time in categorical analyses (RR crude: 1. 3; Cl 95 \% 1.1, 1.7; RR adjusted: 1.3; Cl 95 \% 1.0, 1.6). For boys, an association was found between psychological wellbeing and onset of insufficient activity 2 years later (RR crude: 1.3; Cl 95 \% 1.2, 1.4; RR adjusted: 1.2; Cl 95 \% 1.1, 1.4).

Conclusion: Adolescence is crucial for the development of unhealthy behaviours related to psychological well-being status in the context of a middle-income country. Gender differences are important because poor psychological wellbeing seems to affect sedentary behaviour in girls more than in boys, and predicts insufficient activity among boys.

Keywords: Psychological well- being, Physical activity, Screen time, Adolescents, Longitudinal study

\footnotetext{
* Correspondence: vica_s@hotmail.com

${ }^{1}$ Department of Epidemiology, State University of Rio de Janeiro (UERJ), Rio

de Janeiro, Brazil

Full list of author information is available at the end of the article
} 


\section{Background}

Early adolescence is a critical period for the development and establishment of behaviours and attitudes [1]. Approximately $70 \%$ of young people live in developing countries where complex economic, social, political, and environmental contexts create a wide range of challenges for adolescents to surmount on their journey to adulthood. Worldwide, the proportion of 13-15-year-olds that spend less than $60 \mathrm{~min}$ on moderate and vigorous physical activities (MVPA) per day, and spend more than $2 \mathrm{~h}$ a day in front of television (TV), is $80.3 \%$ and about $65 \%$, respectively [2]. In Brazil, the National Survey of Health of the School (PeNSE) (2012) [3], reported that $70 \%$ of schoolchildren do not meet the recommended level of MVPA and about $80 \%$ spent excessive time in front of TV [4].

Collectively, the research suggests that MVPA for at least $60 \mathrm{~min}$ per day would help children and youth maintain a healthy profile. The documented health benefits include increased physical fitness (both cardiorespiratory fitness and muscular strength), reduced body fat, favourable cardiovascular and metabolic disease risk profiles, enhanced bone health, and reduced symptoms of depression [5]. The decrease of MVPA during adolescence is a consistent finding in the literature, being greater in girls at the beginning of adolescence [6], concomitant with an increasing amount of media exposure and sedentary behaviours [7]. While declines in MVPA have been repeatedly documented, less research attention has been directed toward understanding determinants leading to adolescent disengagement from activity and healthier behaviours. Furthermore, persistence of these unhealthy behaviours through adolescence and early adulthood is detrimental to health and well-being, and it has been shown to be associated with a less healthy lifestyle course $[8,9]$.

Research on determinants of physical activity has burgeoned in the past two decades, but has mostly focused on socio-demographic factors in high-income countries [10]. Given the estimates that approximately one in five young people under the age of 18 experience some form of developmental, emotional, or behavioural problems, added to the fact that neuropsychiatric disorders are a leading cause of health-related burden [11], there is a need to assess whether poor psychological well-being can influence young people to become less active and more sedentary or to persist with these behaviours during adolescence, in the context of a middle income country.

Psychological well-being of adolescents refers to being content with life and experiencing an abundance of positive emotions; when combined with the absence of psychological disorders, it is linked with the highest academic functioning, social skills and support, and physical health. For this reason, psychological well-being is very important for adolescence because it influences the development of a strong personality in the future, as well as influencing which life goals, values, direction, and purpose in life are selected [12].

Although the mechanisms and causal direction underlying the association between psychological well-being and inactive behaviour are still not clear, the following theories are cited: deficiency of serotonin and endorphins associated with decreases in hardiness; reduced stress reactivity; and related decreases in control, mastery, and self-efficacy to adapt and persist in activity [13]. Another particular factor that could lead to low physical activity is the psychological response accompanying the physical changes related to pubertal development $[14,15]$.

In addition, there is consistent evidence that there are differences between boys and girls in cognitive and behavioural coping at the beginning of adolescence [16]. Ryan and Connell [17] found that 8-12-year-old boys reported significantly more activities involving physical exercise than girls, whereas girls reported more social support and emotional behaviour than boys. Thus, gender represents a meaningful variable in research involving the coping strategies of young adolescents [18].

A growing number of studies confirm the power of well-being scales to predict outcomes related to health and lifestyle. Much recent research has found generally positive associations between psychological well-being and MVPA, as well as negative associations with sedentary behaviours [19-21]. Rothon et al. [22] found that more than $60 \%$ of adolescents with mood disorders and $40 \%$ of those with anxiety disorders reported low levels of MVPA. However, most of these studies were conducted in the context of European and Northern American countries with cross-sectional designs, not allowing a more robust discussion about the direction of association between variables and of causality. Thus, longitudinal designs, with more than one measurement of physical activity and sedentary behaviour outcomes, may yield more powerful conclusions.

In view of the above information, the aim of this study was to evaluate whether initial poor psychological wellbeing in early adolescence would be associated with the onset and persistence of insufficient activity and exceeding recommended screen time assessed 2 years later, and whether these associations would differ depending on gender.

\section{Methods \\ Study design}

The Longitudinal Study of Adolescent Nutritional Assessment (ELANA) is a longitudinal study following adolescents from two cohorts, a middle school cohort (age at baseline: 10 to 15 years) and a high school cohort 
(age at baseline: 13.5 to 19 years), at two public and four private schools from the metropolitan region of Rio de Janeiro, Brazil. Regarding the middle school cohort, during the follow-up period adolescents were assessed four times, during 2010-2013. The main aim of the ELANA was to examine changes in anthropometric indicators and body composition, as well as to study the influence of factors such as dietary intake, physical activity, alcohol and tobacco, and socioeconomic and psychosocial conditions on inadequate development and nutritional status.

This study included data from the middle school cohort at baseline, 2010 (Time1 = T1), and 2012 (Time $2=\mathrm{T} 2$ ). At T1, a self-report questionnaire was administered for the study of psychological well-being, physical activity, sedentary behaviour, and socioeconomic variables among respondents. Physical activity and sedentary behaviour measurements were repeated at $\mathrm{T} 2$.

This research was conducted according to the guidelines laid down in the Declaration of Helsinki and all procedures involving human subjects were approved before the start of the examinations by the Ethics Committee in Research of the Institute of Social Medicine of the State University of Rio de Janeiro (certificate number 0020.0.259.000-09). Written informed consent was obtained from adolescents' legal guardians.

\section{Study sample}

Out of 946 adolescents available, 888 met the eligibility criteria of not having a physical or mental condition preventing the completion of questionnaires and/or not being pregnant or lactating at the time. Of the 888 eligible adolescents, 32 (3.6\%) refused to participate, 46 (5.2\%) did not have parental consent, and four $(0.45 \%)$ were without birth date information, leading to a population study of 810 students $(91.2 \%)$ at baseline.

For the present study, 786 adolescents completed information on both psychological well-being and outcomes (physical activity and sedentary behaviour) at T1, corresponding to a response rate of $88.5 \%$. At T2 we retrieved information on physical activity and sedentary behaviour for 526 adolescents, representing a $33 \%$ decrease in participation. The data used in the current study is restricted to those adolescents who participated in both waves and had full information on all study variables $(n=526)$. Information about those who did not answer outcome questions from T1 to T2 can be found in Appendix (Fig. 1).

\section{Data collection \\ Outcomes}

Physical activity Physical activity was assessed with the self-reported 'International Physical Activity Questionnaire

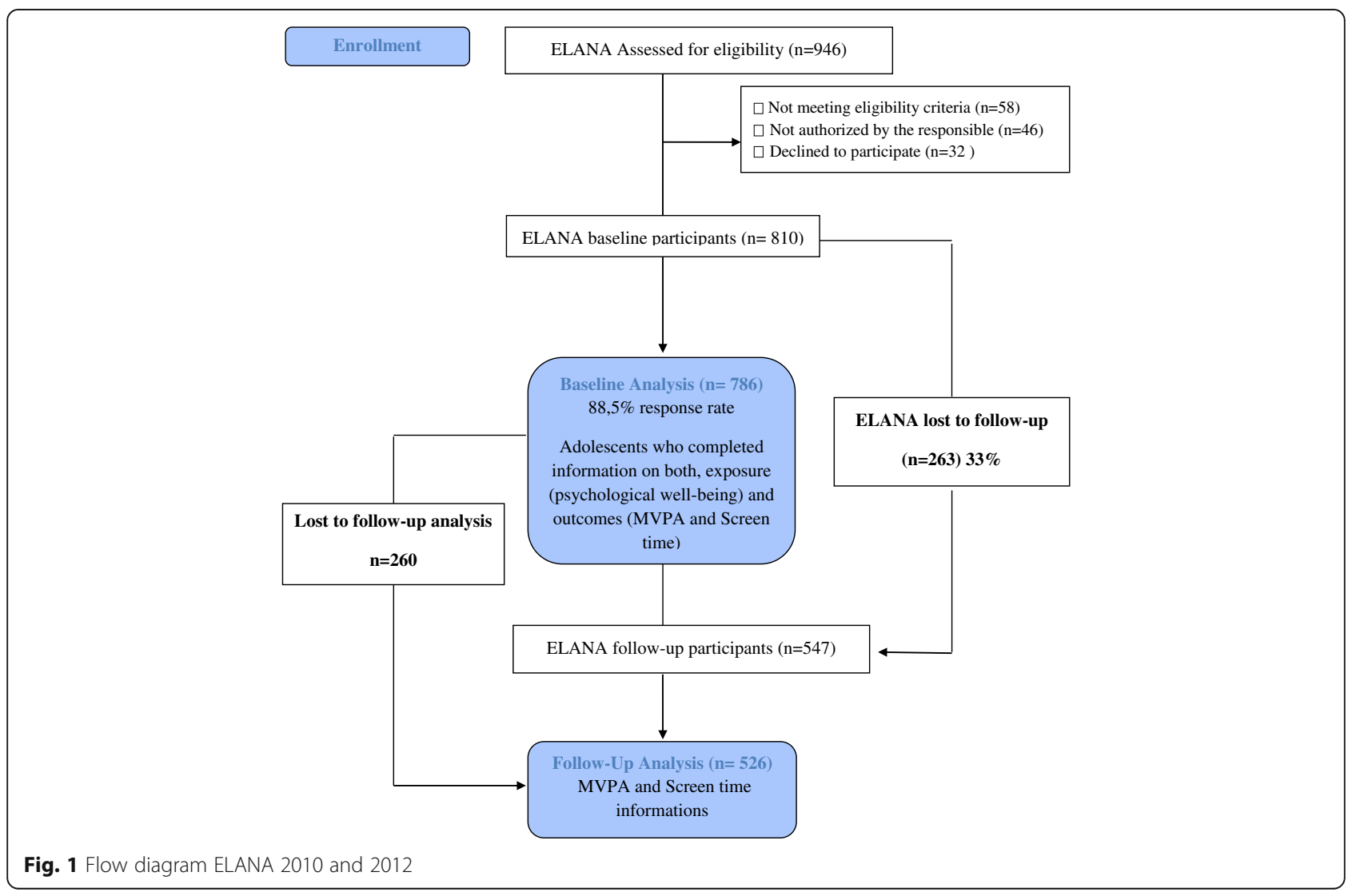


(IPAQ)' at T1 and T2. A short version of the IPAQ with eight open questions was used allowing us to estimate time spent in different physical activities (walking and physical efforts of moderate and vigorous intensity) and physical inactivity (sitting position) during the last 7 days.

This questionnaire was validated for Brazilian adolescents older than 14 years old by Guedes et al. [23]. When blank answers and unusual values for responses (e.g. adolescent told perform $5 \mathrm{~h}$ of moderate to intense physical activity per day) were detected, the research supervisor returned to the student in order to check the coherence of the response to avoid loss of information and error in the classification of the individual. The duration (minutes) of moderate and vigorous physical activity (MVPA) per day reported by adolescents was used based on the guidelines for data processing and analyses of the IPAQ [24]. The adolescents who did not meet the recommendation of $60 \mathrm{~min}$ a day of MVPA were classified as 'insufficiently active' [5].

Sedentary behaviour (Screen time) The time watching television (TV) and using videogames/computers, designated 'screen time', was determined by a self-reported questionnaire comprising two questions at $\mathrm{T} 1$ and $\mathrm{T} 2$ [25]. The first question was 'How many days do you watch TV and videogames/computers per week?' The answers were categorized using a five-point scale for TV and videogames/computers: (1) almost never or never, (2) 1 to 2 times per week, (3) 3 to 4 times per week, (4) 5 to 6 times per week, and (5) every day. The intervals were converted into days per week as follows: category $1=$ no days (almost never or never), $2=1.5$ days, $3=$ 3.5 days, $4=5.5$ days, $5=7$ days.

The second question was 'In general, how many hours do you usually spend watching $T V$ and videogames/computers per day?'. Average daily time in minutes was calculated by multiplying 'hours per day' by 'days per week' for TV and videogames/computers applying this formula: [(days per week)*(hours per day)]*60/7, utilized as a continuous variable. Those who spent more than $4 \mathrm{~h}$ of screen time per day were classified as 'exceeding recommended screen time'.

\section{Independent variables}

Psychological well-being Psychological well-being was evaluated at T1 through the KIDSCREEN, a self-report questionnaire, designed to evaluate generic health related quality of life of children and adolescents [26]. The KIDSCREEN-27 was developed as a short version of the full version (KIDSCREEN-52) and comprises five dimensions of Rasch scales: Physical Well-Being (5 items), Psychological Well-Being (7 items), Autonomy and Parents (7 items), Peers and Social Support (4 items), and School
Environment (4 items). The sub-dimension of psychological well-being used for this study is related to positive or negative attributes regarding emotional symptoms, life satisfaction, as well as feelings of sadness and loneliness. Whereas all the items in a particular area are indicators of a single one-dimensional latent trait, it is reasonable to use each domain in isolation for individual diagnostic interpretations targeted to an area of particular interest [27]. The questionnaire posed questions regarding the last week and for each item five options were provided on a 5 -point Likert scale from $1=$ never to $5=$ always or from $1=$ not at all to $5=$ extremely. From the raw scores, $\mathrm{t}$ values were calculated, based on the Rasch model [27]; lower scores reflected worse psychological well-being. Scores of psychological well-being were dichotomized into 'poor' or 'good' psychological well-being. The 'poor' category was composed of individuals with scores of psychological wellbeing up to the $10^{\text {th }}$ percentile, and the 'good' category of those classified into percentiles higher than the $10^{\text {th }}$, forming the reference category.

\section{Covariates}

The following covariates were tested in the analysis: age, type of school, assets indicator, sexual maturation, and Body Mass Index (BMI). We included age in models as a continuous variable. We used type of school (private or public) as a proxy for socioeconomic status, because in Brazil, socio-demographic and economic characteristics directly impact selection of the type of school.

The economic characteristics of the families of adolescents were also represented by an indicator constructed from information on ownership of durable assets in the home according to the methodology used by Szwarcwald et al. [28], calculated with a weighted equation considering presence or absence of colour TV, VCR or DVD player, radio, bathroom, automotive, washing machine, refrigerator, and freezer (independent appliance or part of a duplex refrigerator). We used a dichotomized form of the assets indicator variable, once smoothing via polynomial split showed a clear difference between the first and the other quintiles on the psychological well-being Tscores, described by Agathão [29], in this sample. There was a marked slope from the first to the second quintile, followed by a plateau, justifying the category of 'less asset ownership' for the first quintile, as well as the 'more asset ownership' category for the other quintiles [29].

A validated self-assessment questionnaire [30] was employed to measure sexual maturation by using gender-specific line drawings of the stages of puberty [31]. This assessment was performed as a categorical variable (pre-pubescent, early spurt, maximum speed peak, and slowing growth). The BMI $\left(\mathrm{kg} / \mathrm{m}^{2}\right)$ was calculated based on direct measurements of height and weight according to Gordon and colleagues' protocol 
[32]. BMI was included in the models as a dichotomous variable, comprising low/normal weight $(\mathrm{BMI}<25)$ and overweight/obese $(\mathrm{BMI} \geq 25)$ [33].

\section{Data analysis}

Descriptive statistics were provided by calculating the means and $95 \%$ confidence intervals $(95 \% \mathrm{CI})$ for the continuous variables and the frequencies for count variables. Comparisons between genders were performed with independent samples t-tests and Chi Square Tests. Paired t-tests were applied to evaluate differences between means of minutes of MVPA and screen time from T1 to T2.

For continuous variables, two models were developed considering the following outcomes: 1 ) minutes per day of MVPA at T2, and 2) screen time minutes per day at T2. The variable minutes of MVPA at T1 was included in the model of MVPA outcomes (1) and screen time minutes per day at $\mathrm{T} 1$ for the screen time model at T2 (2) to adjust for baseline levels of these variables. Other possible confounders (age, sexual maturation, BMI, assets indicator, type of school) were tested for both models and only those with statistical significance $(p<0.20)$, were included in the final models, following a stepwise method to select the variables. As the most important variable for this criterion is not necessarily statistically significant, we imposed an upper limit on the $p$-values (the usual values are in the range [0.15-0.25]) for these variables, so that we selected candidates important in principle to the analysis.

Due the fact that the distribution of the variables was not normal (Kolmogorov-Smirnov test $p<0.05$ ), the Log of the background variables and outcomes were used to perform linear regression procedures to determine the coefficients $(\beta)$ and $r^{2}$ values. Inverse $\log$ values of $\beta$ and $r^{2}$ were presented to allow easier interpretation of the results.

Categorical analyses were also performed using the outcomes of insufficient activity and exceeding recommended screen time, with both analyses using psychological well-being at $\mathrm{T} 1$ as the independent variable. Two different approaches were used for each outcome. The first approach evaluated the onset of insufficient activity and exceeding recommended screen time at T2 (those who were sufficiently active or stayed within the recommended screen time at $\mathrm{T} 1$ who became inactive or exceeded recommended screen time per day at T2). For the onset analyses those who were insufficiently active and those who exceeded the recommended screen time at T1 were not considered. The second approach assessed persistence in being insufficiently active and exceeding recommended screen time at $\mathrm{T} 2$ (those who were insufficiently active or who exceeded the recommended screen time at $\mathrm{T} 1$ and maintained the same behaviour at T2). Only those were insufficiently active and exceeded the recommended screen time at $\mathrm{T} 1$ were considered for persistence analyses. Crude models for MVPA (onset and persistence) included the variable of minutes per day of MVPA at T1; screen time models (onset and persistence) added screen time minutes at T1, and age to adjust for these variables. The adjusted models tested the same variables and criteria as the continuous models.

To estimate the relative risks (RR) and their $95 \% \mathrm{CI}$, we ran Poisson regression models using the sandwich estimator procedure. All statistical analyses were stratified by gender. Statistical analyses were performed using SPSS version 22.0 (SPSS Inc., Chicago, IL, USA).

\section{Results}

The mean age was $11.0(10.9-11.1)$ years old for girls and $11.2(11.0-11.3)$ years old for boys at T1. A summary of the descriptive statistics is shown in Tables 1 . Statistically significant differences were observed in the comparison between the means of minutes of MVPA from T1 to T2 for both girls $(\mathrm{T} 1=43.9$ (38.4-49.5); T2 $=29.5$ (24.7$34.3) ; p<0.001)$ and boys ( $\mathrm{T} 1=66.0(58.7-73.3) ; \mathrm{T} 2=42.1$ (37.2-46.9); $p<0.001)$, and also between the means of screen time minutes per day from T1 to T2 in both genders (boys: $\mathrm{T} 1=320.9(293.6-348.2)$. T2 $=355.5$ (326.3384.7), $p=0.026$; girls: $\mathrm{T} 1=301.1 \quad(271.1-331.1), \mathrm{T} 2=$ 381.1 (348.9-413.3), $p<0.001$ ) (Table 1).

Among girls who were sufficiently active $(N=56)$ and did not exceed the recommended screen time $(N=119)$ at $\mathrm{T} 1,67.8 \%(\mathrm{~N}=38)$ became insufficiently active and $38.6 \%(N=46)$ exceeded recommended screen time minutes at T2. Females who remained insufficiently active (T1: $N=192)$ and who exceeded recommended screen time (T1: $N=128)$ from $\mathrm{T} 1$ to $\mathrm{T} 2$ were $87.5 \%(N=168)$ and $53.1 \%(N=68)$, respectively. Among boys who were sufficiently active $(N=100)$ and did not exceed the recommended screen time $(N=133)$ at $\mathrm{T} 1,74 \%(N=74)$ became insufficiently active and $33.8 \%(N=45)$ exceeded the recommended screen time at T2. Persistence of insufficient activity (T1: $N=172)$ and exceeding recommended screen time (T1: $N=137)$ in males was $73 \%(N=126)$ and $63.5 \%(N=87)$, respectively.

The linear regression analyses showed a significant inverse association between psychological well-being scores and screen minutes per day at T2 among girls $\left(r^{2}=0.049 /\right.$ $\beta=-3.81(95 \%$ CI $-7.0,-0.9))$. The inclusion of screen time at $\mathrm{T} 1$, significant in the model $(\beta=0.15$ (95\% CI $0.02,0.3)$ ), did not alter the significance of the final model. Models based on screen time at T2, adjusted for screen minutes per day at T1 explained $4.9 \%$ of the variance in screen time in girls, and $16 \%$ among boys (in a nonsignificant model). There was no association between psychological well-being scores and minutes per day with 
Table 1 Characterization of sample by sex: middle school cohort, ELANA study, 2010 and (2012)

\begin{tabular}{|c|c|c|c|}
\hline Variables & Male $N=277$ & Female $N=249$ & $P$ value \\
\hline \multicolumn{4}{|l|}{ T1 (2010) } \\
\hline Age (Cl $95 \%)$ & $11.2(11.0-11.3)$ & $11.0(10.9-11.1)$ & $0.037^{a}$ \\
\hline \multicolumn{4}{|l|}{ Sexual maturation (\%) } \\
\hline Pre-pubescent & 5.8 & 6.4 & \multirow[t]{4}{*}{$<0.001^{b}$} \\
\hline Early spurt & 73.1 & 28.9 & \\
\hline Maximum speed peak & 16.3 & 47.0 & \\
\hline Slowing growth & 4.4 & 17.7 & \\
\hline \multicolumn{4}{|l|}{ Type of school (\%) } \\
\hline Public & 30.7 & 30.9 & \multirow[t]{2}{*}{$0.953^{b}$} \\
\hline Private & 69.3 & 69.1 & \\
\hline \multicolumn{4}{|l|}{ Assets Indicator (\%) } \\
\hline Less asset ownership & 25.3 & 12.7 & \multirow[t]{2}{*}{$<0.001^{b}$} \\
\hline More asset ownership & 74.7 & 87.3 & \\
\hline \multicolumn{4}{|l|}{$\mathrm{BMI}\left(\mathrm{Kg} / \mathrm{m}^{2}\right)$} \\
\hline Mean (Cl $95 \%)$ & $20.6(20.1-21.2)$ & $20.2(19.7-20.7)$ & \multirow[t]{2}{*}{$0.265^{\mathrm{a}}$} \\
\hline Normal (\%) & 82.4 & 87.8 & \\
\hline Overweight/obesity (\%) & 17.6 & 12.2 & $0.090^{\mathrm{b}}$ \\
\hline \multicolumn{4}{|l|}{ MVPA (min/day) } \\
\hline Mean (Cl $95 \%)$ & $66.0(58.7-73.3)$ & 43.9(38.4-49.5) & \multirow[t]{2}{*}{$<0.001^{\mathrm{a}}$} \\
\hline$>60 \mathrm{~min} /$ day $^{c}(\%)$ & 36.5 & 22.5 & \\
\hline$\leq 60 \mathrm{~min} /$ day $((\%)$ & 63.5 & 77.5 & $<0.001^{\mathrm{b}}$ \\
\hline \multicolumn{4}{|l|}{ Screen time (min/day) } \\
\hline Mean (Cl $95 \%)$ & $320.9(293.6-348.2)$ & $301.1(271.1-331.1)$ & \multirow[t]{2}{*}{$0.337^{\mathrm{a}}$} \\
\hline$\leq 4$ h/day ${ }^{c}(\%)$ & 48.0 & 53.6 & \\
\hline$>4 \mathrm{~h} /$ day $(\%)$ & 52.0 & 46.4 & $0.199^{b}$ \\
\hline \multicolumn{4}{|l|}{ Psychological well-being } \\
\hline Mean (Cl $95 \%)$ & $49.5(47.5-50.1)$ & $50.2(48.8-51.4)$ & \multirow[t]{2}{*}{$0.405^{\mathrm{a}}$} \\
\hline Poor (\%) & 12.3 & 13.3 & \\
\hline Good $(\%)^{c}$ & 87.7 & 86.7 & $0.737^{b}$ \\
\hline \multicolumn{4}{|l|}{ T2 (2012) } \\
\hline \multicolumn{4}{|l|}{ MVPA (min/day) } \\
\hline Mean (Cl $95 \%)$ & $42.1(37.2-46.9)$ & $29.5(24.7-34.3)$ & \multirow[t]{2}{*}{$<0.001^{\mathrm{a}}$} \\
\hline$>60 \mathrm{~min} /$ day $^{\mathrm{c}}(\%)$ & 26.0 & 13.3 & \\
\hline$\leq 60 \mathrm{~min} /$ day $((\%)$ & 74.0 & 86.7 & $<0.001^{\mathrm{b}}$ \\
\hline \multicolumn{4}{|l|}{ Screen time (min/day) } \\
\hline Mean (Cl $95 \%)$ & $355.5(326.3-384.7)^{d}$ & $381.1(348.9-413.3)^{d}$ & $0.245^{a}$ \\
\hline$\leq 4$ h/day ${ }^{c}(\%)$ & 43.7 & 39.8 & \\
\hline$>4$ h/day (\%) & 56.3 & 60.2 & $0.362^{b}$ \\
\hline
\end{tabular}

Cl $95 \%$ confidence interval $95 \%$, BMI body mass index, MVPA moderate and vigorous physical activity; ${ }^{\mathrm{a}} \mathrm{T}$ test for independent sample by gender; ${ }^{\mathrm{b}} \mathrm{Qui}$ Square test by gender; ${ }^{\mathrm{c}}$ Reference category- Highers scores of psychological well-being; ${ }^{\mathrm{d}}$ Significant difference between means over time $(p<0,05)$-Pared $\mathrm{T}$ test

MVPA at T2 for both genders, and the models explained $1.1-1.8 \%$ of the variance of these variables (Table 2 ).

For those with poorer psychological well-being, the risk of becoming insufficiently active was statistically significant, for both genders, on crude analyses (boy: RR crude 1.3; 95 \% CI 1.2, 1.4/ RR adjusted 1.2; 95 \% CI 1.1, 1.4; girls: RR crude 1.2; $95 \%$ CI 1.1, 1.3). Regarding the association between the onset of exceeding recommended screen time and psychological well-being, statistical differences were observed among girls in crude (RR 
Table 2 Coefficient $(\beta)$ of linear regression, $r^{2}$ and $p$ value for the association between MVPA and screen time with psychological well-being by gender. ELANA study, 2010 and (2012)

\begin{tabular}{|c|c|c|c|c|c|c|}
\hline \multirow[t]{3}{*}{ Variables } & \multicolumn{6}{|c|}{ Psychological well-being } \\
\hline & \multicolumn{3}{|l|}{ Males } & \multicolumn{3}{|c|}{ Females } \\
\hline & $\bar{B}$ & $r^{2}$ & $\mathrm{Cl} 95 \%$ & $\bar{B}$ & $r^{2}$ & Cl $95 \%$ \\
\hline MVPA at 2012 (min/day) & 0.27 & 0.018 & $-0.2-0.7$ & 0.22 & 0.011 & $-0.2-0.7$ \\
\hline MVPA at 2010 (min/day) & 1.0 & & $-0.8-0.8$ & 0.69 & & $-0.04-0.7$ \\
\hline Screen Time at 2010 (min/day) & 0.02 & & $0.0-0.04$ & - & & - \\
\hline Screen Time at 2012 (min/day) & -0.44 & 0.161 & $-3.3-2.4$ & -3.81 & 0.049 & $-7.0--0.9$ \\
\hline Screen Time at 2010 (min/day) & 0.36 & & $0.2-0.5$ & 0.15 & & $0.02-0.3$ \\
\hline BMI $\left(\mathrm{Kg} / \mathrm{m}^{2}\right)$ & 9.10 & & $2.6-15.5$ & - & & - \\
\hline
\end{tabular}

$\beta$ coefficient of linear regression, $r^{2}$ coefficient of determination, MVPA moderate and vigorous physical activity, $B M I$, body mass index, $C l$ confidence interval

1.3; $95 \%$ CI 1.1, 1.7), as well as in adjusted models (RR 1.3 ; 95 \% CI 95 \% 1.0, 1.6). No associations were demonstrated between persistence of both types of undesired behaviour and psychological well-being in boys and girls (Tables 3 and 4).

\section{Discussion}

This study examined the relationship between psychological well-being at baseline and amount of MVPA and screen time 2 years later, evaluating the onset and persistence of insufficient activity and exceeding recommended screen time in the context of a middle-income country. We also investigated whether these relationships differed between genders.

Marked declines are evident among youth, with surveys showing steadily decreasing proportions meeting minimum recommended levels of self-reported physical activity [34]. In addition, steep age-related declines are apparent in both cross-sectional $[35,36]$ and longitudinal studies among adolescents and pre-adolescents [37, 38], being in line with the results from the present study.

Leighton and Swerisson [39], who examined students' perceived changes in physical activity, found $42 \%$ of students reported a relative decline from high school to university. Another study also observed that one third of students declined into insufficient activity during the transition to university [40]. Our sample with children at the beginning of adolescence has shown higher percentages concerning the decline of MVPA per day in boys (74 \%) and girls (67.8 \%) indicating an important change of behaviours during this phase, in this social economic context target.

Regarding results about physical activities changes in the context of low/middle income countries, as in the present study, the first prospective data were from Brazil. The authors found that boys increased their leisure-time physical activity level over the 4 years (mean $75 \mathrm{~min} /$ week; $95 \%$ CI 49, 100), whereas a decrease was observed among girls (mean $-42 \mathrm{~min} /$ week; $95 \% \mathrm{CI}$ $-57,-28)$ [41].

We also find significant differences related to screen time over 2 years, in line with a longitudinal study of American girls aged between 12 and 14 years old that showed an increase from 7.7 to $8.5 \mathrm{~h}$ per day in sedentary behaviour [42]. Mitchell and colleges [43] also found significant changes over time related to sedentary behaviour measured objectively in both genders, evaluated in the United Kingdom at ages 12, 14, and 16. One explanation

Table 3 Relative risks (RR) and $95 \%$ confidence intervals (95\% Cl) of exposure to psychological well-being at T1 (2010) - tertiles and frequencies of onset and persistence of insufficiently active by gender. ELANA Study 2010 and 2012

\begin{tabular}{|c|c|c|c|c|c|c|c|c|}
\hline \multirow{3}{*}{$\begin{array}{l}\text { Psychological } \\
\text { well-being }\end{array}$} & \multicolumn{4}{|c|}{ Onset of insufficiently active } & \multicolumn{4}{|c|}{ Persistence of insufficiently active } \\
\hline & Not became & Became & & & Not persist & Persist & & \\
\hline & N (\%) & N (\%) & Crude RR (95 \% Cl) & Adjusted RR $(95 \%$ Cl) & N (\%) & N (\%) & Crude RR (95 \% Cl) & Adjusted RR $(95 \%$ Cl) \\
\hline \multicolumn{9}{|l|}{ Male } \\
\hline Poor & $0(-)$ & $6(5.9)$ & $1.3(1.2-1.4)$ & $1.2(1.1-1.4)$ & $7(4.0)$ & $21(11,9)$ & $1.0(0.8-1.2)$ & $1.0(0.9-1.2)$ \\
\hline Good $^{1}$ & $26(25.7)$ & $69(68.3)$ & $1.0-$ & $1.0-$ & $39(22.2)$ & $109(61.9)$ & $1.0-$ & $1.0-$ \\
\hline \multicolumn{9}{|l|}{ Female } \\
\hline Poor & $0(-)$ & $4(7.1)$ & $1.2(1.1-1.3)$ & $1.1(0.9-1.4)$ & $3(1.6)$ & $26(13.5)$ & $1.0(0.9-1.1)$ & $1.0(0.9-1.2)$ \\
\hline Good $^{1}$ & $9(16.1)$ & $43(76.8)$ & $1.0-$ & $1.0-$ & $21(10.9)$ & $143(74.1)$ & $1.0-$ & $1.0-$ \\
\hline
\end{tabular}

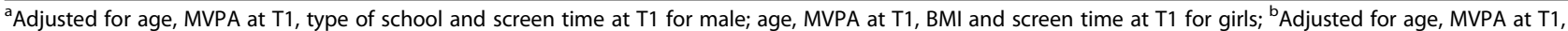
BMI, type of school and screen time at T1 for male; age, MVPA at T1, assets indicator and screen time at T1 for female; ${ }^{1}$ Reference category 
Table 4 Relative risks (RR) and $95 \%$ confidence intervals (95\% Cl) of exposure to psychological well-being at T1 - tertiles and frequencies of onset and persistence of screen time by gender. ELANA Study 2010 and 2012

\begin{tabular}{|c|c|c|c|c|c|c|c|c|}
\hline \multirow{3}{*}{$\begin{array}{l}\text { Psychological } \\
\text { well-being }\end{array}$} & \multicolumn{4}{|c|}{ Onset of Screen Time } & \multicolumn{4}{|c|}{ Persistence of Screen Time } \\
\hline & \multirow{2}{*}{$\begin{array}{l}\text { Not became } \\
\mathrm{N}(\%)\end{array}$} & \multicolumn{3}{|l|}{ Became } & \multirow{2}{*}{$\begin{array}{l}\text { Not persist } \\
N(\%)\end{array}$} & \multicolumn{3}{|l|}{ Persist } \\
\hline & & $N(\%)$ & Crude RR (95 \% Cl) & Adjusted RR $(95 \%$ Cl) & & N (\%) & Crude RR (95 \% Cl) & Adjusted RR $(95 \% \mathrm{Cl})$ \\
\hline \multicolumn{9}{|l|}{ Male } \\
\hline Poor & $8(6.1)$ & $9(6.8)$ & $1.1(0.9-1.5)$ & $1.1(0.8-1.5)$ & $8(5.6)$ & $9(6.3)$ & $0.8(0.6-1.1)$ & $0.8(0.7-1.1)$ \\
\hline Good $^{1}$ & $69(52.3)$ & $46(34.8)$ & $1.0-$ & $1.0-$ & $34(23.8)$ & $92(64.3)$ & $1.0-$ & $1.0-$ \\
\hline \multicolumn{9}{|l|}{ Female } \\
\hline Poor & $10(7.5)$ & $3(2.3)$ & $1.3(1.1-1.7)$ & $1.3(1.0-1.6)$ & $6(5.2)$ & $14(12.2)$ & $1.0(0.8-1.3)$ & $1.0(0.8-1.2)$ \\
\hline Good $^{1}$ & $61(45.9)$ & $59(44.4)$ & $1.0-$ & $1.0-$ & $31(27.0)$ & $64(55.7)$ & $1.0-$ & $1.0-$ \\
\hline
\end{tabular}

${ }^{a}$ Adjusted for age, screen time at T1, BMI, type of school and MVPA at T1 for male; age, screen time at T1 assets indicator, sexual maturation and MVPA at T1 females; ${ }^{b}$ Adjusted for age, screen time at T1, assets indicator, BMI and MVPA at T1 for male; age, screen time at T1, type of school and MVPA at T1 for female; ${ }^{1}$ Reference category

for the significant increase of sedentary behaviour, especially screen time among adolescents, could be that the habit of watching TV has always had a significant social impact on the lives of children and adolescents [44]. Additionally, it should be noted that in recent years the time spent in sedentary activities among adolescents has increased largely due to excessive hours spent on computers, tablet devices, interactive games, and social media [45].

Our results did not verify an association between psychological well-being and MVPA for both genders, when considering the models with continuous variables. However, considering the categorical approach, poorer psychological well-being was associated with onset of insufficient activity in boys, and in girls only in the crude model. The literature has demonstrated conflicting results regarding this relationship. A study performed by Rothon et al. [22] with adolescents from East London indicated no significant association between changes in level of physical activity and odds of depressive symptoms at follow-up. Additionally, there was no evidence in this study for reverse causality; participants who became depressed between baseline and follow-up did not have higher odds of changing their physical activity levels.

In contrast, Bray and Born [41] found that adolescents who self-reported becoming insufficiently active during the first 2 months of transition between the end of adolescence to adulthood life, also reported lower levels of vigour and higher levels of fatigue when compared with those who had continued to be active 2 months after baseline. These researchers also published results from the same sample referring to 7 months after baseline, and insufficiently active students also reported lower levels of psychological well-being at the beginning of the study [8].

Another issue to consider that may justify controversy results in the literature is that some individual and contextual aspects related to MVPA could cause different coping strategies to deal with psychological problems. Research conducted in the Nordic context with Finnish adolescents (16 and 18 years old at baseline and follow up, respectively) showed that among girls who had psychosocial problems at baseline, these problems are simultaneously associated with a higher level of MVPA [46]. A systematic search indicated evidence that habitually active individuals are positively impacted by psychological stress, increasing their level of physical activity, and those at the beginning stages of practice tend to exercise less. Consequently, psychological stress may have a differential impact on exercise adoption, maintenance, and relapse [47].

Regarding psychological well-being and screen time, the literature is more consistent than for MVPA. We found associations between low psychological well-being and the onset of exceeding the recommended screen time among girls. In girls, psychological well-being seems to have more of an effect in determining sedentary behaviours. Among females, strategies to regulate emotions, particularly in early adolescence, are less likely to use distraction/recreation involving corporal movements, such as physical activity and aggression than their male counterparts [48]. A systematic review of the associations between health indicators and screen-based time among adolescent girls suggested a negative relationship between psychological well-being and screen time; however, more longitudinal studies are necessary [49]. One possible explanation of the underlying causes is that adolescent girls with specific symptoms of depression (e.g. feeling tired; finding it hard to initiate activities) may withdraw from social activities, preferring more solitary pursuits such as screen technologies over time [49]. Hume et al. [50] reported that Australian girls (14.4 years \pm 0.61 ) with depressive symptoms in 2004 reported significantly higher TV, video, and DVD viewing in 2006. Another longitudinal study conducted in the Netherlands with 663 students (ages 12 to 15 years) observed that girls who 
reported more loneliness were particularly vulnerable to the onset of compulsive internet use 6 months later [51].

Currently, it is common to see adolescents of both genders playing videogames, using tablets/computers, and accessing social media in Brazil; however, the use of these types of screen technology among girls seems to be a more recent phenomenon in Brazil [52]. Perhaps for this reason, our results have shown associations among girls only when we consider the outcome 2 years later, not the persistence of this behaviour. Another economic issue to be discussed is that Brazil is a middle-income country with high taxes for media technologies and imported products, thereby tending to receive and incorporate novel technologies later than developed countries [52].

To the best of the authors' knowledge, the current work is the first to evaluate the role of psychological well-being over time in MVPA and screen time in a sample of adolescents in Brazil. The longitudinal design allowed for new interpretations on the subject, reducing the possibility of reversed causality, which is an important strength of this study.

A few limitations of this study should be taken into account. Firstly, our results are based on self-reported information about physical activity and screen time. Selfreport questionnaires present some limitations regarding the ability of adolescents to remember, interpret, and quantify physical activity $[53,54]$. Despite recommendations that research combine the strengths of both selfreport and objective measures to provide new insights into the benefits of physical activity and how to implement successful interventions, the majority of public health physical activity guidelines are based on selfreport [55].

Secondly, the use of the IPAQ for adolescents younger than 14 years could be a limitation, since the validation study in Brazil suggests its application for adolescents older than 14 years [24]. Despite a plethora of self- or proxy-reported measures of physical activity for younger people, there is no internationally accepted standard for the measurement of physical activity in adolescents younger than 14 years old. One of the additional challenges is that variations in scoring protocols make it very difficult to compare results between studies [56]. Therefore, we decided to use the IPAQ for adolescents younger than 14 years, checking the coherence of the responses immediately after completion, minimizing biases and inconsistencies in the answers, as some others Brazilian studies have done [57-59]. Thirdly, a large proportion of individuals did not complete the measurement of physical activity and screen time at $\mathrm{T} 2$, reducing the sample by $33.1 \%$. Meanwhile, school changes by students are very common in Brazil, making it difficult to follow them, and these are probably not related to the outcomes or the other variables being investigated.

\section{Conclusion}

Our study identified gender differences in the associations between psychological well-being and the outcome behaviours. The present study highlights the associations between initial poor psychological well-being and the onset of exceeding the recommended screen time 2 years later in girls. This information strengthens prior findings in the literature, and shows an important and new phenomenon among female adolescents in a middleincome context. Sedentary behaviour guidelines for youth may need to be regularly updated, reflecting the rapid technological changes and the significant engagement of adolescents in social media.

Specific strategies focusing on gender differences should be applied for prevention and intervention programs to increase physical activity levels, since prior poor psychological well-being in boys seems to have more negative effects on their MVPA, considering the criteria of public health guideline recommendations.

These results suggest important implications for public health, since the understanding of the determinants that affect physical activity and sedentary behaviours can assist in developing prevention initiatives focused on adolescent health and conduct of the work of school managers. Moreover, considering the consequences of unhealthy behaviors have for health throughout the life course, such as the development of chronic diseases, which, in turn, result in staggering costs to the public health management, evaluative and interventional epidemiological actions focused on preventive practices far beyond healing, become crucial in the current Brazilian health scenario.

Future studies should continue prioritizing longitudinal methodologies so that we can advance in knowledge of the physical activity epidemiology. Approaches that consider longer periods, covering all stages of adolescence and the joint use of direct measures of assessment of physical activity and sedentary (accelerometer) and questionnaires to obtain less biased and more complete information on these constructs. Modern and robust tools for data analysis should be explored in order to study complex scenarios more clearly.

\section{Appendix}

\section{Characterization dropout from $\mathrm{T} 1$ to $\mathrm{T} 2$}

About the missing between T1 $(N=786)$ and T2 (2012) $(N=526)$, among these 260 individuals was observed a difference in the distribution by gender (boys: $55.9 \%$ vs girls: $44.1 \%, p=0.007$ ), but there was no difference in the distribution by type of school (public: $51.3 \%$ vs private: $48.7 \%, p=0.540$ ). The average of minutes per day spent with screen time between those did not continued at T2 was 361.1 (328.3-349.3), 68.2 \% of these did not 
meet the daily recommendations of PA and the average score of psychosocial being was 47.6 (40.2-53.1).

\section{Abbreviations}

BMI: Body mass index; Cl: Confidence interval; ELANA: Longitudinal study of adolescent nutritional assessment; IPAQ: International physical activity questionnaire; MVPA: Moderate and vigorous physical activity; PeNSE: National Survey of Health of the School; RR: Relative risk; T1: Time 1; T2: Time 2; TV: Television

\section{Acknowledgments}

This study was funded by the National Council for Scientific and Technologica Development, the Research Support Foundation of the State of Rio de Janeiro and Coordination for the Improvement of Higher Education Personnel. We also thank the International Cooperation Program between a Brazilian federal government agency research and the Swedish Foundation for International Cooperation in Research and Higher Education (CAPES/STINT - Process 012/13) and the research assistants who participated in data collection and management of the ELANA Study.

\section{Funding}

The ELANA was funded by the National Council for Scientific and Technological Development (grant 47667/2011-9), the Research Support Foundation of the State of Rio de Janeiro (grants E26/ 110 847/2009, E26/110.626/2011 and E-26/110.774/2013) and Coordination for the Improvement of Higher Education Personnel (grant 23038.007702/20115).The funders had no role in study design, data collection and analysis, decision to publish, or preparation of the manuscript.

\section{Availability of data and materials}

The dataset supporting the conclusions of this article is available in response to the request from the researchers admitted by the ELANA committee.

\section{Authors' contributions}

VSS retrieved and critically analysed the studies within the review. VSS drafted the manuscript. AJO, MR and CSL supervised the study and assisted with the analysis and interpretation of the reviewed studies. All authors critically reviewed drafts of the manuscript. All authors read and approved the final manuscript.

\section{Authors' information}

VSS is currently a Ph.D. student at Department of Epidemiology- State University of Rio de Janeiro (UERJ), Rio de Janeiro- Brazil and also a student visiting researcher at Centre for Health and Equity Studies (CHESS), Stockholm/ Sweden, through the International Cooperation Program between a Brazilian federal government agency research and the Swedish Foundation for International Cooperation in Research and Higher Education (CAPES/STINT). VSS's qualifications include a Bachelor of Physiotherapy and a Master of Human Nutrition- Nutritional Epidemiology. AJO (Ph.D.) is Professor at Department of Physical Education and Sports- Rural Federal University of Rio de Janeiro (UFRRJ), Rio de Janeiro-Brazil. MR (Ph.D.) is Professor of Public Health Science specialising Social Epidemiology, Assistant Director at Centre for Health and Equity Studies (CHESS), Stockholm-Sweden. CSL is Associated Professor at Department of Epidemiology- State University of Rio de Janeiro (UERJ), Rio de Janeiro- Brazil.

\section{Competing interests}

The authors declare that they have no competing interests.

\section{Consent for publication}

All parents or legal guardians signed a consent term authorizing the participation of adolescents and publication of scientific information from the study, without participant's identification.

\section{Ethics approval and consent to participate}

Our study protocol and informed consent procedure were approved by the Ethics Committee in Research of the Institute of Social Medicine of the State University of Rio de Janeiro (certificate number 0020.0.259.000-09).

\section{Author details}

'Department of Epidemiology, State University of Rio de Janeiro (UERJ), Rio de Janeiro, Brazil. ${ }^{2}$ Laboratory of Social Dimensions Applied to Physical
Activity and Sport (LABSAFE), UFRRJ, Seropédica, Brazil. ${ }^{3}$ Center for Health and Equity Studies (CHESS), Stockholm, Sweden.

Received: 8 March 2016 Accepted: 29 August 2016

Published online: 15 September 2016

\section{References}

1. Currie C, Nic Gabhainn S, Godeau E. The health behaviour in school-aged children: WHO Collaborative Cross-National (HBSC) study: origins, concept, history and development 1982 - 2008. Int J Public Health. 2009;54(2 sppl):131-9.

2. Hallal PC, Andersen LB, Bull FC, et al. Global physical activity levels: surveillance progress, pitfalls and prospects. Lancet. 2012;380:247-57. http://dx.doi.org/10. 1016/S0140-6736(12)60646-1.

3. Brasil. Instituto Brasileiro de Geografia e Estatística. Pesquisa Nacional de Saúde do Escolar (PeNSE)-2012. Rio de Janeiro: IBGE; 2013.

4. Malta DC, Andreazzi MARD, Oliveira-Campos M, Andrade SSCDA, Sá NNBD, Moura LD, et al. Trend of the risk and protective factors of chronic diseases in adolescents, National Adolescent School-based Health Survey (PeNSE 2009 e 2012). Rev Bras Epidemiol. 2014;17:77-91.

5. WHO. Global recommendation on physical activity for health. Geneva: World Health Organization (WHO); 2010.

6 Dumith SC, Gigante DP, Domingues MR, Hallal PC, Menezes AM, Kohl HW. Predictors of physical activity change during adolescence: a 3.5-year followup. Public Health Nutr. 2012;15(12):2237-45.

7. Taveras EM, Field AE, Berkey CS, Rifas-Shiman SL, Frazier AL, Colditz GA, Gillman MW. Longitudinal relationship between television viewing and leisuretime physical activity during adolescence. Pediatrics. 2007;119(2):e314-9.

8. Bray SR, Kwan MY. Physical activity is associated with better health and psychological well-being during transition to university life. J Am Coll Heal. 2006;55(2):77-82.

9. Tremblay MS, Colley RC, Saunders TJ, Healy GN, Owen N. Physiological and health implications of a sedentary lifestyle. Appl Physiol Nutr Metab. 2010; 35(6):725-40.

10. Bauman AE, Reis RS, Sallis JF, Wells JC, Loos RJ, Martin BW, Lancet Physical Activity Series Working Group, et al. Correlates of physical activity: why are some people physically active and others not? Lancet. 2012;380(9838):258-71.

11. Kieling C, Baker-Henningham H, Belfer M, Conti G, Ertem I, Omigbodun O, et al. Child and adolescent mental health worldwide: evidence for action. Lancet. 2011;378(9801):1515-25.

12. Khan Y, Taghdisi MH, Nourijelyani K. Psychological Well-Being (PWB) of school adolescents aged 12-18 yr, its correlation with general levels of Physical Activity (PA) and socio-demographic factors in Gilgit, Pakistan. Iran J Public Health. 2015;44(6):804-13.

13. Paluska SA, Schwenk TL. Physical activity and mental health. Sports Med. 2000;29(3):167-80.

14. Davison KK, Werder JL, Trost SG, Baker BL, Birch LL. Why are early maturing girls less active? Links between pubertal development, psychological wellbeing, and physical activity among girls at ages 11 and 13. Soc Sci Med. 2007;64(12):2391-404. doi:10.1016/j.socscimed.2007.02.033.

15. Piko B. Gender differences and similarities in adolescents' ways of coping. The Psychological Record, 2001;51(2):223.

16. Ryan RM, Connell JP. Perceived locus of causality and internalization: examining reasons for acting in two domains. J Pers Soc Psychol. 1989:57(5):749.

17. Eschenbeck H, Kohlmann CW, Lohaus A. Gender differences in coping strategies in children and adolescents. J Individ Differ. 2007:28(1):18-26.

18. Hassmen P, Koivula N, Uutela A. Physical exercise and psychological wellbeing: a population study in Finland. Prev Med. 2000;30(1):17-25.

19. Brodersen NH, Steptoe A, Williamson S, Wardle J. Sociodemographic, developmental, environmental, and psychological correlates of physical activity and sedentary behavior at age 11 to 12. Ann Behav Med. 2005;29(1):2-11.

20. Ussher MH, Owen CG, Cook DG, Whincup PH. The relationship between physical activity, sedentary behaviour and psychological wellbeing among adolescents. Soc Psychiatry Psychiatr Epidemiol. 2007;42(10):851-6.

21. Biddle SJ, Asare M. Physical activity and mental health in children and adolescents: a review of reviews. Br J Sports Med. 2011;45(11):886-95.

22. Rothon C, Edwards P, Bhui K, Viner RM, Taylor S, Stansfeld SA. Physical activity and depressive symptoms in adolescents: a prospective study. BMC Med. 2010;8(1):1.

23. Guedes DP, Lopes CC, Guedes JERP. Reprodutibilidade e validade do Questionário Internacional de Atividade Física em adolescentes. Rev Bras Med Esp. 2005;11:151-8. 
24. Patterson E. Guidelines for data processing and analysis of the International Physical Activity Questionnaire - IPAQ (GDPA-IPAQ), 2005. Available from: https://sites.google.com/site/theipaq/scoring-protocol. Accessed 9 July 2011.

25. Currie C, Gabhainn SN, Godeau E, Roberts C, Smith R, Currie D, et al. Inequalities in young people's health: HBSC international report from the 2005/2006 survey. In: Health policy for children and adolescents. Copenhagen: World Health Organization; 2008. p. 5-206.

26. Ravens-Sieberer U, Gosch A, Erhart M, Rueden U, Nickel J, Kurth B-M, et al. The KIDSCREEN questionnaires: Quality of life questionnaires for children and adolescents. Lengerich: Pabst Science Publishers; 2006.

27. Ravens-Sieberer U, Herdman M, Devine J, Otto C, Bullinger M, Rose M, Klasen F. The European KIDSCREEN approach to measure quality of life and well-being in children: development, current application, and future advances. Qual Life Res. 2014;23:791-803.

28. Szwarcwald CL, Leal M d C, Gouveia GC, Souza WVd. Desigualdades socioeconômicas em saúde no Brasil: resultados da Pesquisa Mundial de Saúde, 2003. Rev Bras de Saúde Materno Infantil. 2005;5:s11-22.

29. Agathão BT. Master dissertation: [Percepção da qualidade de vida relacionada à saúde de adolescentes: Um estudo em escolas públicas e privadas do Rio de Janeiro e Niterói, Rio de Janeiro, 2015]. Social Medicine Institute, State University of Rio de Janeiro; 2015.

30. Saito MI. Maturaçäo sexual: auto avaliaçäo do adolescente.Pediatria (Säo Paulo). 1984;6(3):111-5.

31. Tanner JM. Growth at adolescence. 2nd ed. Oxford: Blackwell Scientific publication; 1962.

32. Gordon CC, Chumlea WC, Roche AF. Stature, recumbent length, and weight. Anthropometric standardization reference manual. Champaign: Human kinetics Books; 1988. p. 3-8.

33. De Onis M, Onyango AW, Borghi E, Siyam A, Nishida C, Siekmann J, Development of a WHO growth reference for school-aged children and adolescents. Bull World Health Organ. 2007;85(9):660-7.

34. Knuth AG, Hallal PC. Temporal trends in physical activity: a systematic review. J Phys Act Health. 2009;6(5):548.

35. Caspersen CJ, Pereira MA, Curran KM. Changes in physical activity patterns in the United States, by sex and cross-sectional age. Med Sci Sports Exerc. 2000;32(9):1601-9.

36. Sallis JF, Alcaraz JE, McKenzie TL, Hovell MF. Predictors of change in children's physical activity over 20 months: variations by gender and level of adiposity. Am J Prev Med. 1999;16(3):222-9.

37. Nelson MC, Gordon-Larsen P. Physical activity and sedentary behavior patterns are associated with selected adolescent health risk behaviors. Pediatrics. 2006;117:1281-90.

38. Sigmundová D, El Ansari W, Sigmund E, Frömel K. Secular trends: a ten-year comparison of the amount and type of physical activity and inactivity of random samples of adolescents in the Czech Republic. BMC Public Health. 2011;11(1):731.

39. Leighton $D$, Swerissen $H$. Correlates of vigorous physical activity in young adults during school transition. Aust Psychol. 1995;30:113-7.

40. Bray SR, Born HA. Transition to university and vigorous physical activity: implications for health and psychological well-being. J Am Coll Heal. 2004; 52(4):181-8.

41. Knuth AG, Bacchieri G, Victora CG, Hallal PC. Changes in physical activity among Brazilian adults over a 5-year period. J Epidemiol Community Health. 2009;64:591-5.

42. Treuth MS, Baggett CD, Pratt CA, Going SB, Elder JP, Charneco EY, Webber LS. A longitudinal study of sedentary behavior and overweight in adolescent girls. Obesity. 2009;17(5):1003-8.

43. Mitchell JA, Pate RR, Dowda M, Mattocks C, Riddoch C, Ness AR, Blair SN. A prospective study of sedentary behavior in a large cohort of youth. Med Sci Sports Exerc. 2012;44(6):1081.

44. AAPC. American Academy of pediatrics: children, adolescents, and television. Pediatrics. 2001;107(2):423-6.

45. Babey SH, Hastert TA, Wolstein J. Adolescent sedentary behaviors: correlates differ for television viewing and computer use. J Adolesc Health. 2013;52(1): 70-6.

46. Heikkala E, Remes J, Paananen M, Taimela S, Auvinen J, Karppinen J. Accumulation of lifestyle and psychosocial problems and persistence of adverse lifestyle over two-year follow-up among Finnish adolescents. BMC Public Health. 2014;14(1):542.

47. Stults-Kolehmainen MA, Sinha R. The effects of stress on physical activity and exercise. Sports Med. 2014;44(1):81-121.
48. Hampel P, Petermann F. Age and gender effects on coping in children and adolescents. J Youth Adolescence. 2005;34(2):73-83.

49. Van Den Eijnden RJ, Meerkerk GJ, Vermulst AA, Spijkerman R, Engels RC. Online communication, compulsive Internet use, and psychosocial wellbeing among adolescents: a longitudinal study. Dev Psychol. 2008;44(3):655.

50. Costigan SA, Barnett L, Plotnikoff RC, Lubans DR. The health indicators associated with screen-based sedentary behavior among adolescent girls: a systematic review. J Adolesc Health. 2013;52(4):382-92.

51. Hume C, Timperio A, Veitch J, Salmon J, Crawford D, Ball K. Physical activity, sedentary behavior, and depressive symptoms among adolescents. J Phys Act Heatlh. 2011;8(2):152-6.

52. Junior GC, Cruz DM. Quando a brincadeira vira coisa séria: dos mitos e (in) verdades sobre as relações entre jogos digitais, cultura e consumo. Rev Bras de Ciências do Esporte. 2015 [Epub ahead of print].

53. Farias Júnior JCD, Lopes ADS, Florindo AA, Hallal PC. Validade e reprodutibilidade dos instrumentos de medida da atividade física do tipo self-report em adolescentes: uma revisão sistemática. Cad Saúde Pública. 2010;26(9):1669-91.

54. Aisnworth BC, Caspersen CJ, Mathewwes CE, et al. Recommendations to improve the accuracy of estimates of physical activity derived from self report. J Phys Act Health. 2012;9(1):S76-84.

55. Haskell WL. Physical activity by self-report: a brief history and future issues. J Phys Act Health. 2012;9 Suppl 1:S5-10.

56. WHO. Global strategy on diet, physical activity and health. Geneva: World Health Organization; 2004.

57. dos Santos Amorim PR, de Faria RC, Byrne NM, Hills AP. Physical activity and nutritional status of Brazilian children of low socioeconomic status: undernutrition and overweight. Asia Pac J Clin Nutr. 2006;15(2):217.

58. Straatmann VS, Santos LAV, Palma A, Veiga GV. Cardiorespiratory fitness and physical activity level in adolescents. Rev Bras Cineantropom Desempenho Hum. 2015;17(1):21-30. doi:10.5007/1980-0037.2015v17n1p21.

59. Straatmann VS, Veiga GV. Cardiorespiratory fitness, physical activity and indicator of adiposity in brazilian adolescents. Hum Mov. 2015;16(2):64-70. doi:10.1515/humo-2015-0028.

\section{Submit your next manuscript to BioMed Central and we will help you at every step:}

- We accept pre-submission inquiries

- Our selector tool helps you to find the most relevant journal

- We provide round the clock customer support

- Convenient online submission

- Thorough peer review

- Inclusion in PubMed and all major indexing services

- Maximum visibility for your research

Submit your manuscript at www.biomedcentral.com/submit 